\title{
Species divergence and seasonal succession in rates of mate desertion in closely related Neotropical cichlid fishes
}

\author{
Topi K. Lehtonen • Bob B. M. Wong • Kai Lindström • \\ Axel Meyer
}

\begin{abstract}
Across animal taxa, exclusive female offspring care has evolved repeatedly from biparental care, suggesting that the latter becomes evolutionarily unstable under certain conditions. Both the attributes of a species and the environment it experiences can help to predict shifts from one particular care mode to another. Nevertheless, factors inducing differences in care strategies among closely related species, or seasonal variation within species, have been subject to surprisingly little empirical testing. Here, we report the results of a field-based study that examined both among and within species variation in mate desertion in five species of closely related Nicaraguan cichlid fish in the genera Amphilophus and Amatitlania. The results show a link between female body
\end{abstract}

\section{T. K. Lehtonen K. Lindström}

Department of Biological and Environmental Sciences, 00014 University of Helsinki, Helsinki, Finland

\section{T. K. Lehtonen • A. Meyer}

Lehrstuhl für Zoologie und Evolutionsbiologie, Department of Biology, University of Konstanz,

78457 Constance, Germany

T. K. Lehtonen · B. B. M. Wong

School of Biological Sciences, Monash University,

Melbourne, VIC 3800, Australia

\section{K. Lindström}

Environmental and Marine Biology, Åbo Akademi University, Artillerigatan 6 ,

20520 Turku, Finland

\section{T. K. Lehtonen $(\bowtie)$}

Section of Ecology, Department of Biology,

20014 University of Turku,

Turku, Finland

e mail: topi.lehtonen@utu.fi size and male involvement in offspring care. Specifically, the larger the species the less often males were found to provide extended care. Furthermore, we found that solitary females became more common towards the end of the breeding season. We discuss the implications of this finding in the context of previous theoretical and empirical contributions regarding the frequency of offspring desertion by males.

Keywords Body size $\cdot$ Lake Apoyo - Lake Xiloá · Mate desertion $\cdot$ Midas cichlid complex $\cdot$ Parental care $\cdot$ Seasonal variation $\cdot$ Species comparison

\section{Introduction}

The variance in the reproductive rate of males is typically higher than that of females. As a result, monogamy is often seen as a somewhat unexpected evolutionary outcome for males. The most commonly invoked factors thought to favour male monogamy include low potential for remating and environmental conditions under which investment from both parents is needed for successful offspring care (Smith and Wootton 1995; Whiteman and Côté 2004; Gross 2005). Indeed, monogamy is often associated with biparental offspring care (Smith and Wootton 1995; Reynolds 1996). Nevertheless, if opportunities for polygyny increase, or benefits of continued offspring care decrease, it may become beneficial for the male to desert his current female and offspring (Gross 2005). Hence, the interaction between the intrinsic properties of individuals (or species) and their surrounding environment can be expected to have an important role in determining patterns of polygamy and parental care across different taxa (Reynolds 1996; Gross 2005). In addition, the intensity of sexual selection is also expected to affect the pattern of parental investment; 
whichever sex is subject to stronger sexual selection is likely to provide less care (Kokko and Jennions 2008). In one of the few comparative studies testing for species-specific patterns of parental care, marine invertebrates with small body size were found to provide more extensive parental care than larger species (Strathmann and Strathmann 1982).

Seasonal changes in the biotic or abiotic environment may cause temporal variation in the rates of mate desertion within a species. According to a recent mathematical model by Seno and Endo (2007), which was based on the assumption that mate availability decreases with the progression of the breeding season, the rate of mate desertion is predicted to decrease towards the end of the season. By contrast, an earlier model by Webb et al. (2002), which emphasised the importance of energy reserves in species that are likely to face more than one breeding season, predicted that offspring produced later in the season should be given less care than those produced earlier in the season. To date, however, empirical studies on patterns of mate desertion have mostly been conducted on avian model systems (Houston et al. 2005; Harrison et al. 2009), and tests of seasonal variation are particularly rare (Seno and Endo 2007). In one of the few such studies, Spanish sparrow (Passer hispaniolensis) males were found to desert the female and offspring considerably more often early than late in the season (Marques 2003).

In cichlid fishes (family Cichlidae), exclusive female offspring care has evolved repeatedly from biparental care (Goodwin et al. 1998). Hence, phylogenetic evidence suggests that biparental care has been an unstable breeding strategy. As a group, the family includes species that exhibit biparental care, female-only care, as well as some that may switch between these two strategies (Keenleyside 1991; Goodwin et al. 1998; Kolm et al. 2006a, b; Gonzalez-Voyer et al. 2008). In this regard, cichlid species with labile modes of parental care provide excellent systems for studying patterns of brood care, both among, and within, species (Keenleyside 1991; Gonzalez-Voyer et al. 2008).

In this study, patterns of deviation from biparental offspring care were studied in five species of closely related Nicaraguan cichlids. First, we tested whether size of a species could affect the rate of mate desertion (as measured by the occurrence of solitary females in the field). This was motivated by the prediction that in an environment where predation and competition is rife (e.g. McKaye 1977; Morley and Balshine 2002), (solitary) females of larger species could be better equipped at dealing with the demands of protecting their territory and juveniles (see Nagoshi 1987; Keenleyside 1991). It is also possible that factors correlating with body size, rather than body size per se (see Blanckenhorn 2000, 2005), could influence the prevalence of female-only care. Secondly, we set out to test the two contrasting predictions of Webb et al. (2002) and
Seno and Endo (2007) regarding seasonal success of deviations from biparental care.

\section{Methods}

Underwater observations were conducted in Nicaragua between the beginning of December 2005 and end of January 2006, and between the beginning of December 2007 and end of January 2008 (except where otherwise noted), at depths of $2.5-18 \mathrm{~m}$ using a self-contained underwater breathing apparatus (SCUBA). The study included Amphilophus astorquii (Stauffer et al. 2008) and the arrow cichlid (Amphilophus zaliosus) (Barlow and Munsey 1976; Barluenga et al. 2006) from Lake Apoyo (Fig. 1), and Amphilophus sagittae, Amphilophus xiloaensis (Stauffer and McKaye 2002; Elmer et al. 2009) and Amatitlania siquia (Schmitter-Soto 2007) from Lake Xiloá (Fig. 1). The first four species belong to the Midas cichlid species group (Elmer et al. 2010), which was earlier considered to be strictly monogamous and biparental (McKaye 1977; Rogers 1987, 1988; Barlow 2000). The fifth species, Amatitlania siquia, is a close relative of the Midas cichlid species complex (Říčan et al. 2008). In all these species, males are larger than females and tend to have longer filamentous fin extensions (McKaye 1986; Elmer et al. 2010; personal observations). In Lake Xiloá, Amatitlania siquia females have ventral colour markings that are absent in males which, instead, may have more yellowish base colouration than females (personal observations; see also Beeching et al. 1998). All the remaining species are, by contrast, sexually monochromatic (Barlow 1976; Elmer et al. 2010; personal observations). In these fish, success in territory defence is a central determinant of reproductive output (fitness); during each of their prolonged breading season, they aggressively defend territories in order to protect the offspring against conspecific and heterospecific predators (Barlow 1976; Rogers 1987; Keenleyside 1991; Lehtonen and Lindström 2008; McKaye and Murry 2008). Despite the provision of parental care, a majority of breeding attempts fail as a consequence of predation or territory takeovers, and the rate of new breeding attempts is high for most of the season (McKaye 1977; Lehtonen 2008). Under captive conditions in aquaria, these fish can exceed 10 years of age (personal observations). The fry of successful parents become independent approximately 4 weeks after hatching (Rogers 1987; Wisenden 1995; personal observations).

To record the relative numbers of solitary (deserted) and paired (biparental) females, the observer swam parallel to the shore at a constant depth and counted all broods to his left and right side within a distance of $1.5 \mathrm{~m}$. The species, depth of the breeding territory and status of the female (single 
Fig. 1 Apoyo and Xiloá are crater lakes, i.e. volcano calderas that have filled with water

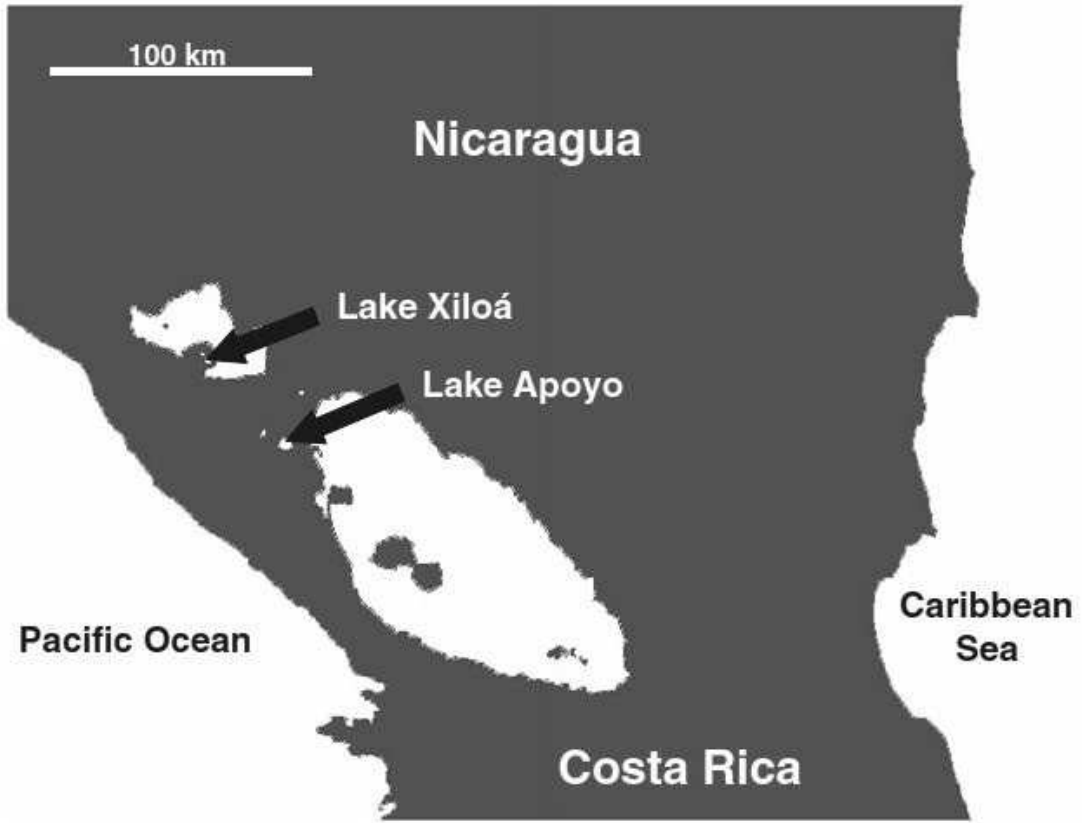

or paired) were recorded. For a subsample $(n=25-33$ for all species except Amphilophus xiloaensis; Fig. 2), we also approximated total lengths of the parents and calibrated our approximations by catching one to four individuals of each species for exact length measurements. In these cases, we tended to overestimate the length of the fish, but never more than by $1.5 \mathrm{~cm}$.

If a lone female guarding her offspring was encountered, the observer backed farther away and ceased all movement in order to determine whether the male was moving somewhere within the proximity of the territory. If there were no sightings of the male within $1 \mathrm{~min}$, we considered the female to be taking care of the offspring alone. For all

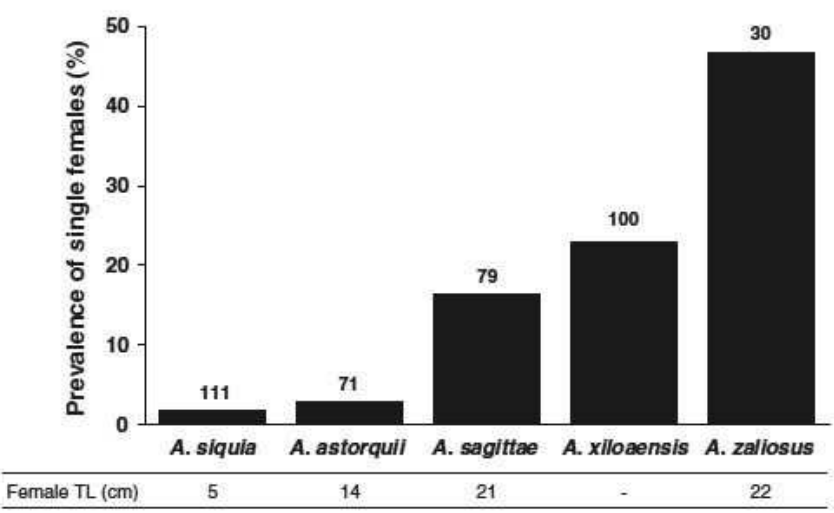

Fig. 2 Prevalence of single females (per brood) for five different cichlid species of crater lakes Apoyo and Xiloá (i.e. Amatitlania siquia, Amphilophus astorquii, Amphilophus sagittae, Amphilophus xiloaensis and Amphilophus zaliosus). Sample sizes are given above each column. Sample sizes for the total length estimates for females of the four species are $33,25,25$ and 27 , respectively solitary arrow cichlid females encountered as well as a few females of the other species, we observed the territory for an additional $15 \mathrm{~min}$ or longer. This control data suggested that the method of waiting $1 \mathrm{~min}$ before judging female status overestimates the number of solitary females by $10 \%$ or less. To prevent successive counts of the same broods, each study site was sampled only once. In the case of Amatitlania siquia, many of the breeding pairs were associated with artificial shelters TKL had earlier placed in the area (see Lehtonen 2008).

We assessed seasonal patterns in the number of solitary females between December 2007 and early February 2008. Because hardly any Amphilophus astorquii or Amatitlania siquia broods under exclusively female care were encountered and because only a very limited number of Amphilo phus zaliosus broods were found during the entire breeding season despite extensive searching effort (over $40 \mathrm{~h}$ of SCUBA diving at areas where the species is known to breed), the seasonal change in the number of single females was only assessed for Amphilophus sagittae ( $n=11$ different sampling dates over the course of the breeding season on average $8.6 \pm 7.5$ (mean $\pm \mathrm{SD}$ ) broods encountered on each occasion) and Amphilophus xiloaensis ( $n=8$ dates with $15.4 \pm 18.1$ broods). The non-overlapping sites around the lake were chosen haphazardly, and the range of depths covered at each site was kept consistent. The relationship between the proportion of solitary females and progression of the breeding season was analysed using analysis of covariance (ANCOVA) on proportion of solitary females, with the number of days since the first sampling treated as a continuous factor and species as a categorical factor. After the interaction between variables 'time passed' and 
'species' was found to be non-significant, we removed it from the model and proceeded with assessing the main effects.

\section{Results}

Distribution of single females among species

There were pronounced differences among the five cichlid species with regard to the prevalence of solitarily parenting females (G-test of independence, $G^{2}=55.6, \mathrm{df}=4, p<0.001$; Fig. 2). Total length approximations provided the following average body sizes from the smallest to the largest species Amatitlania siquia < Amphilophus astorquii $<$ Amphilophus sagittae < Amphilophus zaliosus, which matches exactly with the order of prevalence of single females from the least to most common (Fig. 2). Probability for such a match by chance alone is one in $24, p=0.042$. Concurrent length approximations are not available for Amphilophus xiloaen sis; however, according to Kullander (2003) and our field observations, this species is approximately the same size as Amphilophus sagittae and slightly smaller than Amphilo phus zaliosus (arrow cichlid). The resulting sequence from the smallest to the largest, Amatitlania siquia $<$ Amphilo phus astorquii < Amphilophus sagittaelAmphilophus xiloaensis < Amphilophus zaliosus, accords with the order of prevalence of single females (Fig. 2).

Seasonal change in the number of solitary females

The proportion of broods receiving exclusive female care increased towards the end of the breeding season (ANCOVA, time effect $F_{1,16}=9.38, p=0.007$; Fig. 3). In

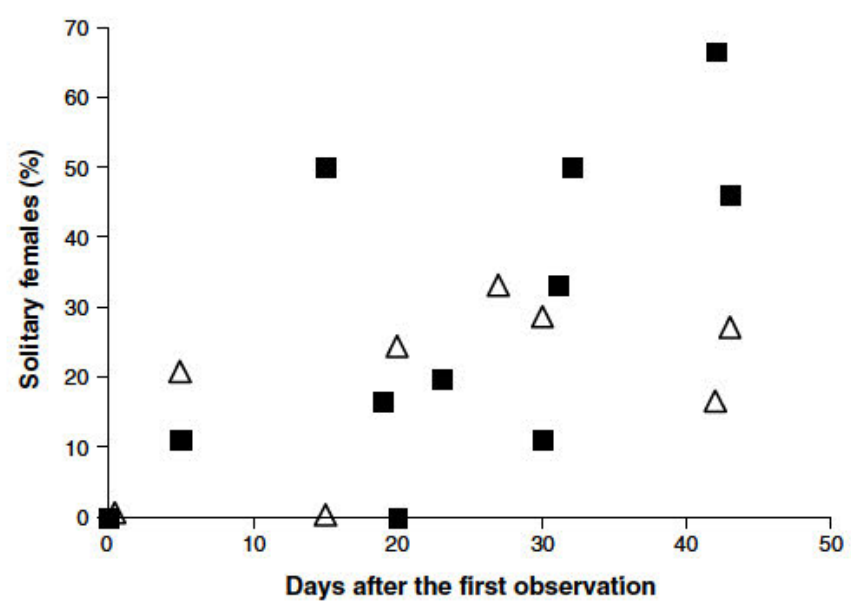

Fig. 3 Seasonal succession of prevalence of solitary females in Amphilophus sagittae (solid squares) and Amphilophus xiloaensis (triangles). Each proportion is calculated from observations made within a single day this respect, there was no significant difference between the two species examined (ANCOVA, species effect $F_{1,16}=$ $1.23, p=0.28)$.

\section{Discussion}

This study revealed that there were pronounced differences among Nicaraguan crater lake cichlids in the proportion of broods receiving exclusive female care. Importantly, it seems that body size, or its correlate, is related to the propensity for males to desert their mates at the species level such that species with smaller body size deviate less from biparental care compared to the larger ones. Interestingly, earlier research also suggests that in the largest cichlid species of Lake Xiloá (McKaye 1977), the wolf cichlid (Parachromis dovii), a clear majority of females defend their broods without participation by the male (van den Berghe and McKaye 2001; personal observations). It is, hence, possible that females of larger species are better equipped to ensure survival of their offspring, making desertion more profitable for males of these species than of species with small females. This hypothesis does not, however, exclude other factors potentially also playing a role in explaining patterns of parental care among species such as differences in general ecology, habitat choice, territorial behaviour, adult sex ratios, probability of extrapair parentage and intensity of sexual selection (e.g. Smith and Wootton 1995; Reynolds 1996; Gross 2005; GonzalezVoyer et al. 2008; Kokko and Jennions 2008).

We also tested for a seasonal success in the prevalence of uniparental females. The theoretical model of Seno and Endo (2007) and two previous empirical studies (Vélez et al. 2002; Marques 2003) suggest that if remating opportunities decrease towards the end of a breeding season, the profitability for the male to leave the current brood should decrease late in the season. By contrast, competition for high-quality territories (which are in limited supply) is likely to ease towards the end of a season (McKaye 1977), which could favour an opposite trend in the prevalence of deviations from biparental care (Whiteman and Côté 2004; Wong et al. 2008). Decreased reproductive value of the offspring produced late in the season (Smith and Wootton 1995; Gross 2005) or decline of energy reserves below a threshold level (Webb et al. 2002) should also select for the latter pattern. The subsequent seasonal increase in the prevalence of deserting males is in accordance with our results; there was a positive relationship between the date of observation and the proportion of broods that were guarded by solitary females. Hence, our findings provide empirical support for the predictions of the theoretical model of Webb et al. (2002) rather than that of Seno and Endo (2007), indicating that, in this system, energy reserves, rather than 
possible changes in mating opportunities, are likely to have an important role in the parental care decisions of males. Our results also accord with those of Morley and Balshine (2002), which indicated that mate availability was not a key factor for the prevailing type of parental care in another cichlid species, Eretmodus cyanosticus (but see e.g. Keenleyside 1983).

Single females were found to be relatively common in species of the Midas cichlid complex even in conditions of high intensity of both breeding space competition and offspring predation (Crater Lake Xiloá: McKaye 1977). Such conditions have earlier been thought to impose monogamous and biparental breeding systems on these fish (McKaye 1977; Rogers 1987, 1988; Barlow 2000). In fact, the lowest prevalence of deserted females was found in Amatitlania siquia, the only one of the five species investigated that previously was known to deviate from biparental care under conditions amenable to male desertion (Keenleyside et al. 1990; Wisenden 1994). Because monogamy and biparental care are often linked, one might predict that deviations from biparental care in these cichlids should also be coupled with male (and possibly female) polygamy. More broadly, the results of this study expose gaps in the current state of knowledge about breeding systems of aquatic and other animals that are not regularly observed in situ and raise the question of how often species thought to be exclusively biparental are, in fact, only facultatively so.

Acknowledgements K. McKaye, E. van den Berghe, J. McCrary and L. López provided working facilities and logistic help in Nicaragua. M. Geiger helped with many of the dives and with the sinking of "Flor de Caña". L.R. Morales Herrera, R.I. Membreño Andino and M. E. Bernal provided additional assistance in the field. The manuscript also benefited from helpful comments by $O$. Svensson, P.A. Svensson and two anonymous reviewers. MARENA, Nicaragua, issued the necessary working permits. Financial support was provided by the Academy of Finland (TKL and KL), the Alexander von Humboldt Foundation of Germany (TKL), Oskar Öflund's Foundation (TKL), the Australian Research Council (BBMW) and the Deutsche Forschungsgemeinschaft (AM). The study complies with the current laws of Nicaragua.

Conflicts of interest The authors declare that they have no conflict of interest.

\section{References}

Barlow GW (1976) The Midas cichlid in Nicaragua. In: Thorson TB (ed) Investigations of the ichthyofauna of Nicaraguan Lakes. University of Nebraska Press, Nebraska, pp 333358

Barlow GW (2000) Cichlid fishes: nature's grand experiment in evolution. Perseus Publishing, Cambridge

Barlow GW, Munsey JW (1976) The red devil Midas arrow cichlid species complex in Nicaragua. In: Thorson TB (ed) Investigations of the ichthyofauna of Nicaraguan Lakes. University of Nebraska Press, Nebraska, pp 359369
Barluenga M, Stölting KN, Salzburger W, Muschick M, Meyer A (2006) Sympatric speciation in Nicaraguan crater lake cichlid fish. Nature 439:719 723. doi:10.1038/nature04325

Beeching SC, Gross SH, Bretz HS, Hariatis E (1998) Sexual dichromatism in convict cichlids: the ethological significance of female ventral coloration. Anim Behav 56:1021 1026. doi:10.1006/anbe. 1998.0868

Blanckenhorn WU (2000) The evolution of body size: what keeps organisms small? Q Rev Biol 75:385 407. doi:10.1086/393620

Blanckenhorn WU (2005) Behavioral causes and consequences of sexual size dimorphism. Ethology 111:977 1016. doi:10.1111/ j. 1439 0310.2005.01147.x

Elmer KR, Lehtonen TK, Meyer A (2009) Color assortative mating contributes to sympatric divergence of neotropical cichlid fish. Evolution 63:2750 2757. doi:10.1111/j.1558 5646.2009.00736.x

Elmer KR, Kusche H, Lehtonen TK, Meyer A (2010) Local variation and parallel evolution: morphological and genetic diversity across a species complex of neotropical crater lake cichlid fishes. Philos Trans R Soc B 365:1763 1782. doi:10.1098/rstb.2009.0271

Gonzalez Voyer A, Fitzpatrick JL, Kolm N (2008) Sexual selection determines parental care patterns in cichlid fishes. Evolution 62:2015 2026. doi:10.1111/j.1558 5646.2008.00426.x

Goodwin NB, Balshine Earn S, Reynolds JD (1998) Evolutionary transitions in parental care in cichlid fish. Proc R Soc Lond B 265:2265 2272. doi:10.1098/rspb.1998.0569

Gross MR (2005) The evolution of parental care. Q Rev Biol 80:37 45. doi:10.1086/431023

Harrison F, Barta Z, Cuthill I, Székely T (2009) How is sexual conflict over parental care resolved? A meta analysis. J Evol Biol 22:1800 1812. doi:10.1111/j.1420 9101.2009.01792.x

Houston AI, Székely T, McNamara JM (2005) Conflict between parents over care. Trends Ecol Evol 20:33 38. doi:10.1016/j. tree.2004.10.008

Keenleyside MHA (1983) Mate desertion in relation to adult sex ratio in the biparental cichlid fish Heterotilapia multispinosa. Anim Behav 31:683 688. doi:10.1016/S0003 3472(83)80223 1

Keenleyside MHA (1991) Parental care. In: Keenleyside MHA (ed) Cichlid fishes, behaviour, ecology and evolution. Chapman \& Hall, London, pp 191208

Keenleyside MHA, Bailey RC, Young VH (1990) Variation in the mating system and associated parental behaviour of captive and free living Cichlasoma nigrofasciatum (Pisces, Cichlidae). Behaviour 112:202 220

Kokko H, Jennions MD (2008) Parental investment, sexual selection and sex ratios. J Evol Biol 21:919 948. doi:10.1111/j.1420 9101.2008.01540.x

Kolm N, Goodwin NB, Balshine S, Reynolds JD (2006a) Life history evolution in cichlids 1: revisiting the evolution of life histories in relation to parental care. J Evol Biol 19:66 75. doi:10.1111/ j.1420 9101.2005.00984.x

Kolm N, Goodwin NB, Balshine S, Reynolds JD (2006b) Life history evolution in cichlids 2: directional evolution of the trade off between egg number and egg size. J Evol Biol 19:76 84 . doi:10.1111/j.1420 9101.2005.00987.x

Kullander SO (2003) Cichlidae (Cichlids). In: Reis RE, Kullander SO, Ferraris CJ Jr (eds) Checklist of the freshwater fishes of South and Central America. EDIPUCRS, Porto Alegre, pp 605654

Lehtonen TK (2008) Convict cichlids benefit from close proximity to another species of cichlid fish. Biol Lett 4:610 612. doi:10.1098/ rsbl.2008.0378

Lehtonen TK, Lindström K (2008) Density dependent sexual selection in the monogamous fish Archocentrus nigrofasciatus. Oikos 117:867 874. doi:10.1111/j.2008.0030 1299.16677.x

Marques PAM (2003) Male mate desertion in the Spanish sparrow Passer hispaniolensis. Ardea 91:245 250 
McKaye KR (1977) Competition for breeding sites between the cichlid fishes of Lake Jiloa, Nicaragua. Ecology 58:291 302. doi: $10.2307 / 1935604$

McKaye KR (1986) Mate choice and size assortative pairing by the cichlid fishes of Lake Jiloá, Nicaragua. J Fish Biol 29(Supplement A):135 150. doi:10.1111/j.1095 8649.1986.tb05005.x

McKaye KR, Murry BA (2008) Sex role differentiation in brood defense by a Nicaraguan cichlid fish, Amphilophus xiloaensis. Caribb J Sci 44:13 20

Morley JI, Balshine S (2002) Faithful fish: territory and mate defence favour monogamy in an African cichlid fish. Behav Ecol Sociobiol 52:326 331. doi:10.1007/s00265 00205200

Nagoshi M (1987) Survival of broods under parental care and parental roles of the cichlid fish, Lamprologus toae, in Lake Tanganyika. Jap J Ichthyol 34:71 75. doi:10.1007/BF02904146

Reynolds JD (1996) Animal breeding systems. Trends Ecol Evol 11:68 72. doi:10.1016/0169 5347(96)81045 7

Říčan O, Zardoya R, Doadrio I (2008) Phylogenetic relationships of Middle American cichlids (Cichlidae, Heroini) based on com bined evidence from nuclear genes, mtDNA, and morphology. Molec Phylogenet Evol 49:941 957. doi:10.1016/j.ympev. 2006.08.012

Rogers W (1987) Sex ratio, monogamy and breeding success in the Midas cichlid (Cichlasoma citrinellum). Behav Ecol Sociobiol 21:47 51. doi:10.1007/BF00324434

Rogers W (1988) Parental investment and division of labor in the Midas cichlid (Cichlasoma citrinellum). Ethology 79:126 142

Schmitter Soto JJ (2007) A systematic revision of the genus Archocentrus (Perciformes: Cichlidae), with the description of two new genera and six new species. Zootaxa 1603:1 78

Seno H, Endo H (2007) A mathematical model on the optimal timing of offspring desertion. J Theor Biol 246:555 563. doi:10.1016/j. jtbi.2007.01.015
Smith C, Wootton RJ (1995) The costs of parental care in teleost fishes. Rev Fish Biol Fisher 5:7 22. doi:10.1007/BF01103363

Stauffer JR Jr, McKaye KR (2002) Descriptions of three new species of cichlid fishes (Teleostei: Cichlidae) from Lake Xiloá, Nicaragua. Cuad Investig UCA 12:1 18

Stauffer JR Jr, McCrary JK, Black KE (2008) Three new species of cichlid fishes (Teleostei: Cichlidae) from Lake Apoyo, Nicaragua. P Biol Soc Wash 121:117 129. doi:10.2988/06 37.1

Strathmann RR, Strathmann MF (1982) The relationship between adult size and brooding in marine invertebrates. Am Nat 119:91 101

van den Berghe EP, McKaye KR (2001) Reproductive success of maternal and biparental care in a Nicaraguan cichlid fish, Parachromis dovii. J Aquaric Aquat Sci 9:49 65

Vélez MJ, Jennions MD, Telford SR (2002) The effect of an experimental brood reduction on male desertion in the Panamanian blue acara cichlid Aequidens coeruleopunctatus. Ethology 108:331 340. doi:10.1046/j.1439 0310.2002.00772.x

Webb JN, Székely T, Houston AI, McNamara JM (2002) A theoretical analysis of the energetic costs and consequences of parental care decisions. Philos Trans R Soc B 357:331 340. doi:10.1098/ rstb.2001.0934

Whiteman EA, Côté IM (2004) Monogamy in marine fishes. Biol Rev 79:351 379. doi:10.1017/S1464793103006304

Wisenden BD (1994) Factors affecting mate desertion by males in free ranging convict cichlids (Cichlasoma nigrofasciatum). Behav Ecol 5:439 447. doi:10.1093/beheco/5.4.439

Wisenden BD (1995) Reproductive behaviour of free ranging convict cichlids, Cichlasoma nigrofasciatum. Environ Biol Fish 43:121 134. doi:10.1007/BF00002480

Wong MYL, Munday PL, Buston PM, Jones GP (2008) Monogamy when there is potential for polygyny: tests of multiple hypotheses in a group living fish. Behav Ecol 19:353 361. doi:10.1093/ beheco/arm141 